\title{
THE ENGLISH SPARROW AS AN AGENT IN THE DIS- SEMINATION OF CHICKEN AND BIRD MITES.
}

\author{
BY H. E. EWING.
}

\section{Observations.}

DURING the summer of 1905 , while the author was engaged in making collections of various external parasites near Arcola, Ill., a large hay-barn was found in which a multitude of English Sparrows had nested. From the roof of the barn there extended upward a large cupola, the inside of which soon proved to be perfectly alive with sparrows. Numerous nestlings were found, either concealed in the some score of large, trashy nest-bundles, so characteristic of the species, and which occupied the various recesses and corners of the wooden structure, or, being now almost full-fledged, had fluttered out of the nests whence their ill spent attempts at flight had caused no small amount of concern on part of the parents. However, as is not usually the case, the sparrows evidently did not have complete possession of this veritable hatching house for their species for a few pigeons had also shared with them the use of this structure, and an examination revealed some three or four nests of these. Luckily for us collectors the cupola was provided with a trap door, so after entering the structure we were enabled to capture several of the live birds and examine them for parasites. None of these birds were killed, but a perfectly enormous number of parasites were secured, and among them was found a very great number of what seemed to be the common poultry louse, or chicken mite, Dermanyssus gallince Redi. Later studies have fully established the correctness of this offhand determination.

Since the sparrow has been recognized for some time as being one of the many hosts of an allied species (Dermanyssus avium DeGeer), for a long while I was inclined to doubt that this mite was the real mite of poultry, yet the near proximity of the haybarn to a chicken-house, which at least for some years had been known to be infested with the chicken mite, strongly suggested to 
me the probability of this species being the one found on poultry.

During the summer of 1909 , while a graduate student in the University of Illinois, I took up the study of these two species of mites mentioned. Arrangements were made with a couple of students to get me the sparrows, but they were unable to get many individuals. However, the author continued to collect what data there was to be obtained beth at Urbana and Arcola, Ill. One day, to my surprise, a sparrow was found that had fallen upon the

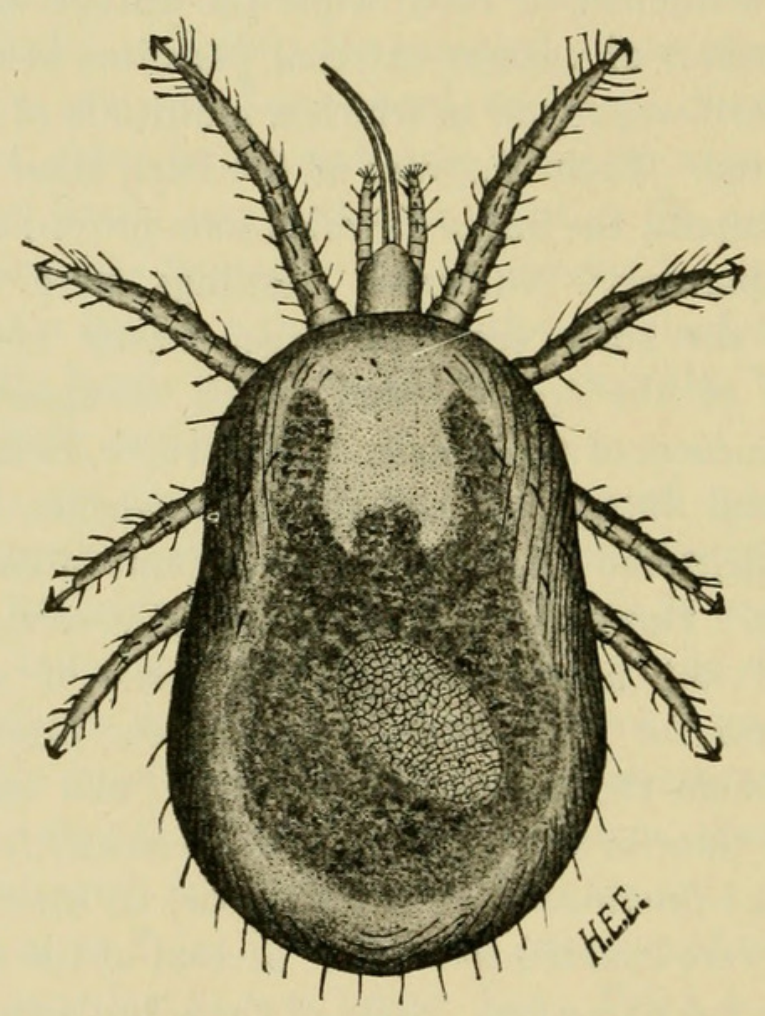

Fig. 1.- Dermanyssus gallina Redi, the common chicken mite of poultryhouses. Dorsal view of female, much magnified.

grass of the campus, and upon examination it was seen to possess scores, if not hundreds, of Dermanyssi. The individual was weak, sickly, and exhausted, and evidently would soon have died from the effects of the attacks of these scores of mites. The bird was killed, however, and the mites collected. Examinations of these specimens later showed that they were no other than Dermanyssus gallina Redi (Fig. 1), our common chicken mite. The work at the University was not completed, because as yet I had failed to get any accurate and reliable characters for the distinction of these 
two closely related species of mites, although I had consulted all the literature available on the subject. Right here, it might be mentioned, that these two species are and have been constantly confused in the literature dealing with each of them.

During the summer of 1910, while at Ames, Ia., frequent reports came in, both from the town of Ames and from other points in the State, of the seriousness of the attacks of the chicken mite upon poultry. An investigation and inquiry in regard to the number of chicken-houses infested showed that while several were per-

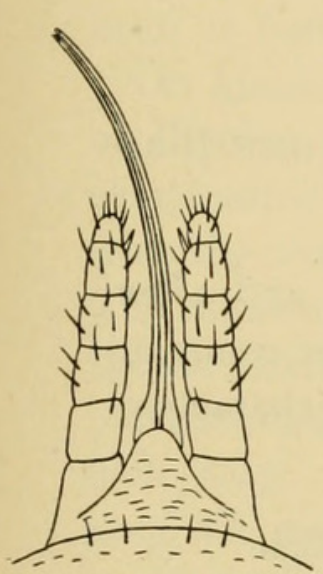

a

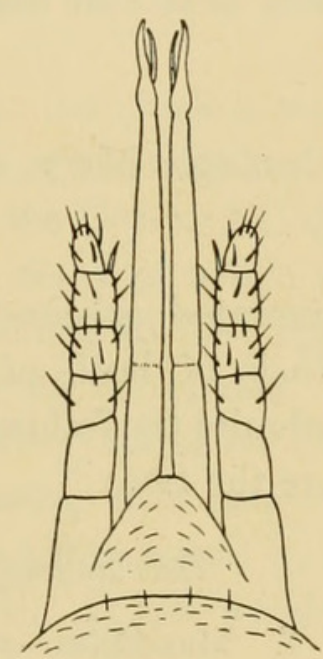

b

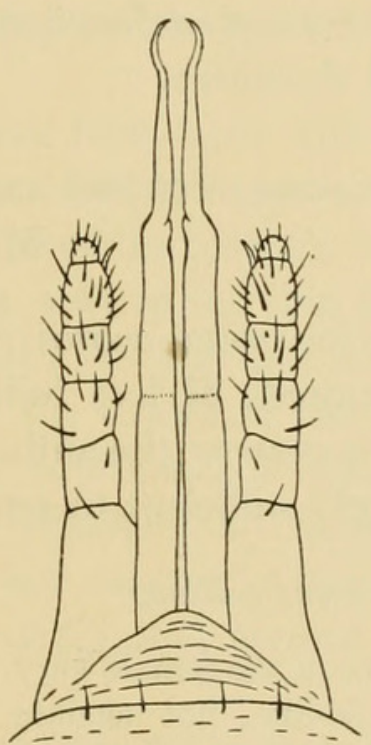

c

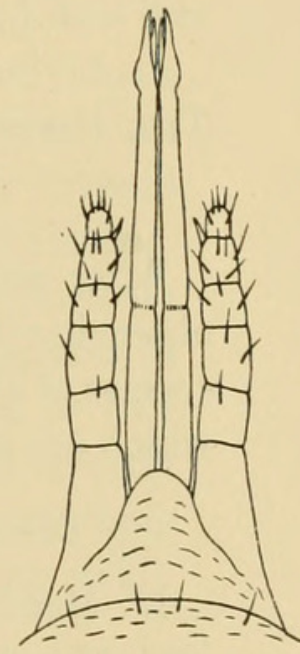

d

Fig. 2.- Mouth-parts of both males and females of the chicken and bird mites: all of the same magnification. a. Dorsal view of the mouth-parts of the female of the chicken mite, showing the long needle-like mandibles protruded. $b$, The same of the female of the bird mite. c. Dorsal view of the mouth-parts of the male of the chicken mite, showing the one long specialized arm of the chela. $d$. The same of the male of the bird mite.

fectly free from the chicken mite many were badly infested. On August 11 a rather large and recently deserted nest of the English Sparrow was found in an old wagon shed entirely separated from any adjoining buildings. This nest was procured and upon examination was found to harbor hundreds, even thousands of the chicken mites. Every feather found on the interior of the nest had scores of mites upon it. A medium sized feather which appeared to be only moderately infested proved to have 72 individuals 
upon it. The number of feathers thus used in the construction of the nest was at least more than 200. I estimated them at 250 . Multiplying this number by the number of individuals found on a single feather would give the total number of 18,000 individuals of the poultry mite fcund in only a single nest of the sparrow.

This case, though the worst found, will give some idea as to what are the possibilities of infestation of a chicken house or roost by means of the sparrow; and of the annoyance which these mites may give to other fowls or domestic animals, and, as I have found in one case, to man himself, when the mites are compelled to leave an abandoned sparrow nest and begin to wander and seek food elsewhere.

\section{The Differences Between the Chicken Mite and the Bird} Mite.

After studying some scores of mounted specimens, and after observing hundreds of live individuals of both of cur common species of Dermanyssus, the author submits the following characters which are amply sufficient to separate the two:

\section{Dermanyssus gallina}

1. Mandibles of the female very long and needle-like, not chelate (Fig. 2,a). [By dorso-ventral pressure they may be protruded.]

2. Mandibles of male, seen to be chelate, but one of the arms of the chelæ especially long drawn out and curved (Fig. 2, c).

3. Females becoming, at times, much larger than the males, often as much as three times, due to engorgement with blood. Length may be over $1.00 \mathrm{~mm}$.

\section{Dermanyssus avium}

1. Mandibles of female very slender but not needle-like, and seen to be distinctly chelate (Fig. $2, b)$.

2. Mandibles of the male, normal, and not differing essentially from those of the female (Fig. 2, d).

3. Females but little larger than males. Never over $1.00 \mathrm{~mm}$. long.

\section{Inoculation Tests.}

Some time previous to the finding of the badly infested sparrow nest, a healthy young chicken was procured for experimental purposes. This chicken was kept in a large, clean goods box for a 
cage. On July 20, 50 individuals of the bird mite, Dermanyssus avium DeGeer, were placed upon the chicken in the cage. These mites were taken from a young robin; plenty of them were also found on sparrows and mourning deves. On the 24th, four days later, a careful examination was made of the chicken, but not a single one of the mites were to be found. The same results were obtained on the 28th and again on August 2. On August 11, three weeks after the original inoculation, not a sign of a mite could be found either upon the chicken, or in the cracks of the box, although if the chicken should have been a natural host to the bird mite, every opportunity for the establishment of the species would have been at hand.

On August 11, the chicken was now inoculated with individuals of Dermanyssus gallina Redi, taken from the sparrow nest. An examination on the 12th and 13th showed the chicken to be covered with the mites, many of which were next to the skin and feeding. The mites continued to feed upon the chicken and multiplied by the hundreds, even thousands. In the cracks of the box and in old knot-holes they could be found sometimes a quarter or half inch deep. During this time the chicken had become greatly annoyed, and at times would be almost constantly busy scratching itself with its bill. It lost weight rapidly, and became very sickly in appearance.

On August 20 many of these mites were taken from the chicken and used to inoculate an English Sparrow which had been kept in confinement, and was free from Dermanyssus gallince Redi. The mites at once began to annoy and feed upon the sparrow. In fact their attacks became so vigorous that the bird soon succumbed, and upon examination after death, before it had become cold, many individuals were found upon its skin and feeding.

Having thus established the fact that the mites found in the sparrow's nest could be inoculated upon the chicken, that the same mites after feeding for a long period upon the chicken could again be inoculated upon the sparrow, I made some observations for testing the ability of Dermanyssi to travel when off of a host, and upon the length of time which they could live when entirely without food. Many individuals of Dermanyssus avium were confined in a small glass cell entirely without food. They apparently did 
not suffer from the abstinence for at least two days, and upon an examination four days later, several individuals were found to be yet alive.

Individuals from both species when placed on the top of a clean table could be found ten minutes later on the floor and at a considerable distance away. Thus within a period of four days it would be seen that these creatures could travel for no inconsiderable distances, as they evidently do when food becomes scarce. From this it would follow that chickens nesting in barns, outhouses, in chicken coops placed near the bases of trees, or in hen-houses in which sparrows were allowed to build would be especially subject to inoculation from the deserted sparrow nests.

\section{Summary.}

1. The English Sparrow frequently harbors and is the host of one of our worst, if not the worst, of poultry pests, the chicken louse or chicken mite, Dermanyssus gallinæe Redi.

2. Sparrows become repeatedly inoculated with these mites from the chicken roosts because of their habit of lining their nests with poultry feathers, many of which have lice upon them, shaken off of the infested chickens when wallowing in the dust, etc.

3. Sparrow nests when built in the vicinity of chicken roosts, upon becoming deserted may leave hundreds or thousands of lice, to seek food and shelter elsewhere. These individuals being very active on their feet and able to sustain themselves for several days away from a host may travel considerable distances and infest new chicken-houses.

4. The English Sparrow likewise harbors and is the host of perhaps the most important of all the external parasites of our native song birds, and likewise of our tamed cage birds, the bird mite, Dermanyssus avium De Geer. 


\section{$2 \mathrm{BHL}$ Biodiversity Heritage Library}

Ewing, H. E. 1911. "The English Sparrow as an Agent in the Dissemination of Chicken and Bird Mites." The Auk 28, 335-340.

https://doi.org/10.2307/4070949.

View This Item Online: $\underline{\text { https://www.biodiversitylibrary.org/item/54988 }}$

DOI: https://doi.org/10.2307/4070949

Permalink: https://www.biodiversitylibrary.org/partpdf/87465

\section{Holding Institution}

Smithsonian Libraries

\section{Sponsored by}

Smithsonian

\section{Copyright \& Reuse}

Copyright Status: Public domain. The BHL considers that this work is no longer under copyright protection.

This document was created from content at the Biodiversity Heritage Library, the world's largest open access digital library for biodiversity literature and archives. Visit BHL at https://www.biodiversitylibrary.org. 